\title{
Radiolytic decomposition of pesticide carbendazim in waters and wastes for environmental protection
}

\author{
A. Bojanowska-Czajka $\cdot$ H. Nichipor $\cdot$ P. Drzewicz $\cdot$ \\ B. Szostek • A. Gałęzowska - S. Męczyńska • M. Kruszewski • \\ Z. Zimek • G. Nałęcz-Jawecki • M. Trojanowicz
}

Received: 15 September 2010/Published online: 28 April 2011

(C) The Author(s) 2011. This article is published with open access at Springerlink.com

\begin{abstract}
The radiolytic degradation of widely used fungicide, carbendazim, in synthetic aqueous solutions and industrial wastewater was investigated employing $\gamma$-irradiation. The effect of the absorbed dose, initial concentration and $\mathrm{pH}$ of irradiated solution on the effectiveness of carbendazim decomposition were investigated. Decomposition of carbendazim in $100 \mu \mathrm{M}$ concentration in synthetic
\end{abstract}

A. Bojanowska-Czajka · P. Drzewicz · S. Męczyńska ·

M. Kruszewski · Z. Zimek · M. Trojanowicz $(\bowtie)$

Institute of Nuclear Chemistry and Technology,

Dorodna 16, 03-195 Warsaw, Poland

e-mail: trojan@chem.uw.edu.pl

H. Nichipor

Institute of Radiation Physical and

Chemical Problems, National Academy

of Science of Belarus, Minsk, Belarus

B. Szostek

DuPont Corporate Center for Analytical Sciences,

Wilmington, DE, USA

G. Nałęcz-Jawecki

Department of Environmental Health

Sciences, Warsaw University of Medicine,

Banacha 1, 02-097 Warsaw, Poland

A. Gałęzowska - M. Trojanowicz

Department of Chemistry,

University of Warsaw, Pasteura 1,

02-093 Warsaw, Poland aqueous solutions required irradiation with $600 \mathrm{~Gy}$ dose. The aqueous solutions of carbendazim have been irradiated in different conditions, where particular active radical species from water radiolysis predominate. The obtained data have been compared with the kinetic modeling. The reversed-phase high-performance liquid chromatography was used for the determination of carbendazim and its radiolytic decomposition products in irradiated solutions. The changes of toxicity of irradiated solutions were examined with different test organisms and human leukemia cells.

Keywords Carbendazim - Ionizing radiation · Radiolytic decomposition · Advanced oxidation process · Toxicity · HPLC

\section{Introduction}

Pesticide residues are detected both in environment (waters, soil), but also in vegetables and fruits, as well as in processed food. Hence constant need for improvement and simplification of analytical methods for determination of pesticides in various samples is obvious, as well as development of technologies for their effective removal from industrial wastes and environmental media.

Fungicides, chemicals used for destruction of unwanted fungi in various applications, are employed in large scale since 1960s, and since then their use constantly increases. Species of most common use for this purpose are thiabendazole, fuberidazole, benomyl, methyl thiophanate and carbendazim [1]. Carbendazim (methyl benzimidazole-2ylcarbamate, MBC) with structure shown below is product of hydrolysis of benomyl (showed below) and also methyl thiophanate. 


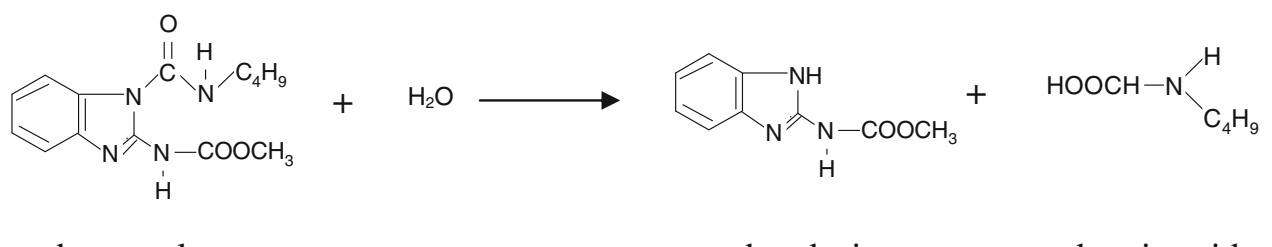

benomyl

carbendazim carbamic acid

Carbendazim is used for protection of crops, fruits and vegetables against fungal diseases, and also for protection of harvested products during their storage and transportation. The toxicity of carbendazim is well documented [2], hence its residues are considered as environmental pollutants. Its biological action is based on inhibition of synthesis of nucleic acids and cell division in fungi. Its teratogenic properties were also shown for different species [3-5]. Carbendazim is slowly decomposing in natural environment, and its decomposition by ambient solar irradiation takes about $300 \mathrm{~h}$, while with UV irradiation this period of time is shortened down to $15 \mathrm{~min}$, with 2-aminobenzimidazol identified as main product of decomposition [6].

Methods of decomposition of carbendazim for environmental protection, described so far in the literature, are based on photolysis by UV irradiation in various chemical conditions [6-10]. The main subject of those works was determination of yield of carbendazim photolysis at different $\mathrm{pH}$ values of irradiated solutions and various concentrations of dissolved oxygen. The efficiency of carbendazim decomposition is facilitated by alkaline $\mathrm{pH}$, where non-dissociated form of substrate is present (protonation constant for carbendazim $\mathrm{pK}_{\mathrm{a}}=4.2$ ), and in the presence of oxygen in irradiated solution [10]. Photolytic decomposition of carbendazim was also investigated in the presence of selected dye-sensitizers, such as Bengal Rose or riboflavin, which in aerobic conditions enhance yield of carbendazim decomposition [11]. The decomposition of carbendazim has been also carried out by ozonation [12].

Analytical determination of carbendazim has been reported in natural waters [13-15], wine [16] and fruits [17, 18]. Determination in environmental samples at $0.1 \mathrm{ppb}$ $(0.52 \mathrm{nM})$ level required solid-phase extraction of analyte [19]. The development of analytical methods for determination of carbendazim did not involve, so far, simultaneous determination of decomposition products of carbendazim, which may be helpful in elucidation of mechanism of decomposition.

The aim of this study was to determine the yield of radiolytic decomposition of carbendazim and its decomposition products using high-performance liquid chromatography (HPLC) with UV detection. Liquid chromatographymass spectrometry (LC-MS) was employed to identify the products of $\gamma$-radiolysis of carbendazim. Another task was also the examination of the effect of different factors affecting the efficiency of radiolytic degradation of carbendazim, including the dose rate, initial concentration and $\mathrm{pH}$ of irradiated solutions. Our earlier works in this field were focused on radiolytic decomposition of chlorophenols $[20,21]$ and chlorophenoxyacid pesticides [22-25]. The additional aspect of this work is examination of toxicity changes of irradiated solution of carbendazim using different toxicity tests responding with different sensitivity to carbendazim and products of its decomposition.

\section{Experimental}

\section{Reagents}

All chemicals used were of highest purity grade available. Carbendazim, 2-hydroxy-benzimidazole, 2-aminobenzimidazole, 1,2-phenylenediamine, 2-methyl-2-propanol and ammonium acetate were purchased from Sigma-Aldrich, while aniline and benzimidazole were purchased from Fluka. All stock solutions were kept at $4{ }^{\circ} \mathrm{C}$ in the dark. HPLC grade acetonitrile (ACN) from JT Bakers was used for the preparation of HPLC eluent. It was filtered through a $0.2 \mu \mathrm{M}$ filter before use.

\section{Apparatus}

\section{Irradiation sources}

For $\gamma$-irradiation a ${ }^{60} \mathrm{Co}$ source Issledovatel from Russia was used with a dose rate of $1.2 \mathrm{kGy} / \mathrm{h}$. In electron beam (EB) irradiation accelerator Elektronika (Russia) with beam energy $8-10 \mathrm{MeV}$ was employed. The dosimetry was carried out with Fricke dosimeter for $\gamma$ source, and cellulose triacetate foil for electron beam.

Irradiation was carried out in $100 \mathrm{~mL}$ conical flasks fully filled with solution (without gas above solution surface), and in $10 \mathrm{~mL}$ custom made flask allowing saturation of irradiated solutions with required gas.

The content of dissolved oxygen in the irradiated solutions was measured using self-stirring oxygen sensor model StirrOx G from WTW (Weilheim, Germany). 


\section{HPLC analysis}

The chromatographic determinations of pesticides and products of their radiolytic decomposition in synthetic samples and waste water samples were performed by reversed-phase HPLC with Shimadzu chromatograph equipped with UV-Vis diode array detector and fluorescent detector RF-10Axl, a Luna ODS2 $250 \times 4.6 \mathrm{~mm}, 5 \mu \mathrm{m}$ analytical column and a guard column from Phenomenex (Torrance, CA, USA), with flow rate $1 \mathrm{~mL} / \mathrm{min}$ in gradient elution. The sample injection volume was $100 \mu \mathrm{L}$ for synthetic solution of carbendazim and $20 \mu \mathrm{L}$ for waste analysis. The optimization of eluent composition is discussed below.

\section{LC-MS analysis}

Identification of carbendazim irradiation products was carried using LC-MS system composed of an Agilent Model 1100 HPLC set-up equipped with a UV-Vis Diode Array Detector (Palo Alto, CA) and a 4000 Qtrap mass spectrometer (Applied Biosystems, Foster City, CA). A Luna C18 (2), $2.0 \times 250 \mathrm{~mm}, 5 \mu \mathrm{m}$ particle size column from Phenomenex (Torrance, CA, USA) was used for HPLC separation. The gradient elution used $10 \mathrm{mM}$ ammonium acetate in water with $5 \%$ acetonitrile (A) and pure acetonitrile (B) with a gradient starting at $95 \%$ $\mathrm{A}-75 \% \mathrm{~A}$ at $30 \mathrm{~min}$, followed by column equilibration with $95 \%$ A from $30.1 \mathrm{~min}$ to $35 \mathrm{~min}$. The flow rate of the mobile phase was $0.25 \mathrm{~mL} / \mathrm{min}$. The MS system was operated in the negative and positive ionization mode with Turbo Spray (electrospray) source, capillary voltage of $4.5 \mathrm{kV}$, and source temperature of $450{ }^{\circ} \mathrm{C}$. To correlate the retention times of known and unknown components observed in the chromatograms obtained with the HPLC analysis and these obtained from LC-MS analysis a set of standards was run on LC-MS and UV spectra were compared for unknown components. For structure elucidation, selected samples were run on an LC-Q-TOF system (Model 2795 Alliance HT HPLC and Q-TOF II mass spectrometer, Waters Corporation, Milford MA) to determine accurate mass of molecular ions and fragment ions of unknown compounds.

For identification of products of radiolytic decomposition LC-MS system was used with hybrid quadrupol-timeof-flight (Q-TOF) analyzer and electrospray ionization. For carbendazim (MW 191) $\mathrm{min} \mathrm{m} / \mathrm{z}$, for main daughter ions were 160.1, 132.1, 105.1 and 92.1, for benzimidazole (MW 118) they are 92.1, and 65.2, for 2-aminobenzimidazole (MW 133)-107.1, 93.1, 92.1, and 65.1, for 2-hydroxybenzimidazole (MW 134)-107.1, 93.1, 92.1, and 80.1, and for aniline (MW 93)—77.0, 67.1 and 51.1

\section{Procedures}

\section{Irradiation}

The 20, 75 and $100 \mu \mathrm{M}$ solutions of carbendazim were prepared for irradiation and the $\mathrm{pH}$ was adjusted to required values with sulfuric acid or potassium hydroxide solutions. A small amount of added sulfate ion does not affect radiolytic decomposition of carbendazim, due to low reactivity of $\mathrm{SO}_{4}{ }^{2-}$ towards primary radicals formed during radiolysis of water $\left({ }^{\bullet} \mathrm{OH}, \mathrm{H}^{\bullet}, \mathrm{e}_{\mathrm{aq}}^{-}\right)$. Precision of absorbed dose for conical flasks for $n=5$ was RSD $2.0 \%$. For vessels used for saturation of sample solution with gases for $95 \%$ confidence level bias was $\pm 3.1 \%$. In all calculation of the absorbed dose in each experiment the decay of activity of ${ }^{60} \mathrm{Co}$ source due to natural decay was taken into account.

\section{Analysis of industrial waste waters}

HPLC measurements of industrial waste waters were carried out after filtration of raw samples and dilution 1:100 with distilled water. No other pretreatment was carried out.

\section{Toxicity measurements}

\section{Daphniae test}

For these measurements the Daphtoxkit $\mathrm{F}^{\mathrm{TM}}$ was employed which is $24-48 \mathrm{~h}$ acute toxicity test, based on cladoceran crustacean Daphnia magna in the form of "dormant eggs (ephippia)". The test is carried out by the use of the "neonates" which are hatched in about 3 days from the eggs. The bioassays are conducted in disposable multi-well test plates and counting alive, immobile and dead species under the microscope. Toxicity was determined before and after irradiation for synthetic solution of carbendazim.

\section{Cell test}

In order to evaluate cytostatic activity of irradiated pesticide solutions a human leukemia cell test was carried out employing tetrazolium 3-[4,5-dimethylotiazol-2-yl]-2,5 diphenyl bromide (MTT) dye, where measured parameter is activity of redox mitochondria. In alive cells this dye is reduced to phormazan appearing as purple crystals. Amount of crystallized phormazan is determined by spectrophotometry at $540 \mathrm{~nm}$ after dissolution. In such measurements EC50 value corresponds to the presence of $50 \%$ of alive cells compared to control cells. 


\section{Results and discussion}

Optimization of HPLC separation

The first step in this work was to develop HPLC method for simultaneous determination of carbendazim and several products of its radiolytic decomposition. Earlier works on photocatalytic decomposition of carbendazim indicated formation of 2-aminobenzimidazole [6-10] and also 4- and 5-hydroxycarbendazim [7, 26]. Reported earlier RP-HPLC method for determination of carbendazim [16] does not permit simultaneous determination of carbendazim and its decomposition products. This can be achieved with twosolution gradient elution employing $10 \mathrm{mM}$ ammonium acetate aqueous solution containing 5\% acetonitrile and pure acetonitrile with gradient from 5 to $25 \%$ in $30 \mathrm{~min}$. In studies of $\mathrm{pH}$ effect on separation satisfactory results can be obtained above $\mathrm{pH}$ 6.0. Taking into account time of analysis $\mathrm{pH} 8.0$ was chosen as optimum, and for $100 \mu \mathrm{L}$ sample injection volume the obtained peaks are symmetrical and well resolved except slight overlapping of signals for 2-hydroxybenzimidazole and benzimidazole. Increase of temperature of HPLC column from 25 to $70{ }^{\circ} \mathrm{C}$ may be used for shortening the analysis time by about $20 \%$, but without significant improvement of resolution. Determinations were carried out with spectrophotometric detection at $277 \mathrm{~nm}$. HPLC determinations were also carried out with fluorescence detection as both carbendazim and many its decomposition products show native fluorescence at used measuring conditions. As it is shown in Table 1, however, significant improvement of limit of detection with fluorimetric detection was observed for 2-hydroxybenzimidazol, only, while for other analytes was comparable or worse, hence UV detection was used mostly in monitoring of radiolytic processes.

In optimized conditions for HPLC determination of carbendazim with UV detection limit of detection was found $0.015 \mu \mathrm{M}$ for injected sample volume $100 \mu \mathrm{L}$, and $0.172 \mu \mathrm{M}$ for $20 \mu \mathrm{L}$ sample volume used in analysis of wastes. It is better result than reported in the literature, so far, as, e.g. for HPLC determination with fluorimetric detection it was reported $0.031 \mu \mathrm{M}$ in surface waters [14], while in wine sample $0.021 \mu \mathrm{M}$ [16].

Effect of irradiation conditions on radiolytic decomposition of carbendazim

Irradiation of aqueous solutions with ionizing radiation $\gamma$ or EB results in radiolysis of water with formation of several reactive products of both oxidative and reductive properties, of which most important are hydroxyl radicals ${ }^{\circ} \mathrm{OH}$, hydrogen radicals $\mathrm{H}$, and solvated electron $\mathrm{e}_{\mathrm{aq}}^{-}$. Reactions of organic target compounds with these species in diluted aqueous solutions leads to decomposition of organic compounds in irradiated solutions. In vast literature on radiolytic processes in aqueous solutions it is shown that yield of radiolytic decomposition depends on numerous factors, including initial concentration of target compound, dose of radiation, presence of scavengers of radicals, and in some cases dose-rate and $\mathrm{pH}$ of irradiated solutions.

Effect of initial concentration was examined in this work for solutions of initial concentrations from 20 to $100 \mu \mathrm{M}$. The choice of investigated concentrations was made taking into account of solubility of carbendazim, as well as the level of concentrations employed for studies of decomposition with other methods. The solubility of carbendazim at $\mathrm{pH} 4$ is $153 \mu \mathrm{M}$ [2], and photochemical decomposition in aqueous solutions was carried out, e.g. at $30 \mu \mathrm{M}$ concentration [10]. Gamma-irradiation was carried out in aerated solutions of $\mathrm{pH}$ 7.0, with initial concentration of oxygen about $8 \mathrm{mg} \mathrm{L}^{-1}$. In these conditions reductive products of water radiolysis $\left(\mathrm{H}^{\circ}\right.$ and $\left.\mathrm{e}_{\mathrm{aq}}^{-}\right)$react with oxygen forming radicals $\mathrm{HO}_{2}^{\bullet}$ i $\mathrm{O}_{2}^{\bullet-}$. The magnitude of absorbed dose required for decomposition of carbendazim increases almost linearly with concentration of carbendazim in the examined range from 20 to $100 \mu \mathrm{M}$ (with correlation coefficient $r^{2}=0.92$ ), which also suggests the same mechanism of decomposition in examined range of concentration.

Table 1 The values of limits of detection (LOD) for carbendazim and expected products of its decomposition in HPLC determination with UV detection at $277 \mathrm{~nm}$, and fluorescence detection at $\lambda_{\mathrm{ex}}=280 \mathrm{~nm}$ and $\lambda_{\mathrm{em}}=320 \mathrm{~nm}$ for injected sample volume $20 \mu \mathrm{L}$

\begin{tabular}{llll}
\hline Analyte & $\begin{array}{l}\text { Retention } \\
\text { time, min }\end{array}$ & $\begin{array}{l}\text { LOD for fluorimetric } \\
\text { detection, } \mu \mathrm{g} \mathrm{L}^{-1}\end{array}$ & $\begin{array}{l}\text { LOD for UV detection } \\
\text { at 277 } \mathrm{nm}, \mu \mathrm{g} \mathrm{L}\end{array}$ \\
\hline 1,2-phenylenediamine & 9.4 & No response & 108 \\
2-aminobenzimidazole & 12.0 & 75 & 64 \\
2-hydroxybenzimidazole & 14.5 & 6 & 46 \\
Benzimidazole & 14.9 & 38 & 69 \\
Aniline & 18.3 & 240 & 184 \\
Carbendazim & 24.0 & 210 & 33 \\
\hline
\end{tabular}

LOD was determined as concentration corresponding to the signal equal triple value of a noise amplitude in recorded chromatograms 
The acidity of irradiated solutions affects only slightly the amounts of formed products of water radiolysis. In strong acidic solutions additional amount of $\mathrm{H}^{\bullet}$ radicals is formed in the reaction of solvated electron with protons, whereas in alkaline solutions increase of concentration of solvated electrons is observed, however, the concentration of ${ }^{\bullet} \mathrm{OH}$ radicals formed is constant in large $\mathrm{pH}$ range [27]. Additionally, $\mathrm{pH}$ of solution may affect protonation equilibrium of irradiated compounds in case of weak acids or bases, which may influence the yield of radical reactions with water radiolysis products. It was reported already in the literature that carbendazim is stable in acidic and neutral media, while it undergoes hydrolysis in alkaline solutions to 2-aminobenzimidazole [28]. In the coarse of this work it was found that at $\mathrm{pH} 10$ about $20 \%$ of carbendazim is hydrolyzed within $20 \mathrm{~h}$. The effect of $\mathrm{pH}$ was also investigated in aerated $100 \mu \mathrm{M}$ solution with gammairradiation in $\mathrm{pH}$ range $3-10$, and no especially pronounced effect was observed on absorbed dose required to complete decomposition. Some increase of yield in alkaline solutions at smaller dose can be attributed to a simultaneous process of carbendazim hydrolysis. Lack of significant effect of $\mathrm{pH}$ is advantageous in comparison to other advanced oxidation processes, which are strongly affected by $\mathrm{pH}$ as for instance photochemical processes [10], because initial $\mathrm{pH}$ adjustment of irradiated sample is not needed, and whole procedure of water or waste treatment is simplified.

It is important from the point of view of elucidation of mechanism of radical reactions to carry out radiolytic experiments in conditions where one particular radical predominates. This can be achieved by conducting irradiation in particular chemical conditions. For instance, when irradiated solution is saturated with nitrous oxide $\mathrm{N}_{2} \mathrm{O}$ practically only ${ }^{\bullet} \mathrm{OH}$ and $\mathrm{H}^{\bullet}$ radicals in the ratio 9:1 exist in solution as reactive species [27, 29]. On the other hand when irradiation is carried out in the presence of $0.2-1.0 \mathrm{M}$ tert-butanol, this reagent acts as effective scavenger of hydroxyl radicals [30].

In this work radiolytic decomposition of carbendazim was examined in conditions where particular radicals predominate (Fig. 1a). The calculated values of radiation chemical yield $(\mathrm{G})$ and required dose for $50 \%$ decomposition $\left(\mathrm{D}_{0.5}\right)$ are showed in Table 2. The most effective conditions are in $\mathrm{N}_{2} \mathrm{O}$ saturated solutions when hydroxyl radicals predominate and $90 \%$ of carbendazim is decomposed at $0.3 \mathrm{kGy}$ dose. This indicates an oxidative mechanism of the decomposition process. In aerated solutions of $\mathrm{pH} 7.0$ at the same dose, $58 \%$ of carbendazim is decomposed. For irradiation carried out in reducing conditions with predominating solvated electrons a further drop of yield was observed. A complete decomposition of carbendazim in $100 \mu \mathrm{M}$ solutions with hydroxyl radicals requires $0.6 \mathrm{kGy}$ dose.
Final products of radiolytic decomposition of carbendazim

For identification of final products of radiolytic decomposition of carbendazim in different chemical conditions HPLC measurements with various detections were employed. In $\gamma$-irradiated aerated $100 \mu \mathrm{M}$ solution of carbendazim at $\mathrm{pH}$ 7.0 with $0.2 \mathrm{kGy}$ dose the same products were identified as in case of solutions saturated with oxygen or $\mathrm{N}_{2} \mathrm{O}$. The solution saturated with $\mathrm{N}_{2} \mathrm{O}$ was most convenient for this purpose as under these conditions concentration of products of radiolysis was the biggest. In recorded chromatograms, based on retention times, among products of radiolysis were identified 2-aminobenzimidazole, aniline, and 2-hydroxybenzimidazole or benzimidazole. In the latter case, based on the UV spectra, peak recorded at $14.7 \mathrm{~min}$ (Fig. 1b) was assigned to 2-hydroxybenzimidazle. At this retention time no signal was recorded in LC-Q-TOF-MS measurements that can be explained by very weak ionization of this compound.

The LC-MS measurements allowed the identification of two signals of unknown compounds recorded at retention times 12.8 and $18.3 \mathrm{~min}$ in carbendazim solutions irradiated in conditions with strong predominance of hydroxyl radicals. In both spectra ions with $\mathrm{m} / \mathrm{z} 208$, and fragment ion 176 are observed. The exact mass for 208 ion was determined as 208.07320 and differs by $1 \mathrm{mDa}$ from ion of elemental composition $\mathrm{C}_{9} \mathrm{H}_{10} \mathrm{~N}_{3} \mathrm{O}_{4}$. Such elemental composition corresponds to protonated carbendazim with added hydroxyl functional group and protonation occurs during the electrospray ionization process. It was also concluded that fragmentation of two 208 ions eluted at different retention times occurs similarly, which does not allow to indicate which retention time corresponds to which isomer of hydroxycarbendazim. Formation of hydroxycarbendazim as products of radical decomposition of carbendazim was also postulated earlier [7, 26].

In conditions with predominated reducing radicals in irradiated solutions, different final radiolysis products are observed compared to the reaction with hydroxyl radicals. Similar radiolysis products were observed when solvated electrons or hydrogen atom were predominant. LC-MS identification of these products was carried in solutions of $\mathrm{pH} 7.0$ saturated with argon, and irradiated in the presence of $1 \%$ tert-butyl alcohol. This allows finding if the HPLC signal with retention time 14.7 corresponds to 2-hydroxybenzimidazole or benzimidazole. Both recorded MS spectra (Fig. 1c) and UV spectra indicate presence of benzimidazole. Additionally, analysis of MS spectra obtained for signals at retention time 18.4 and $25.3 \mathrm{~min}$ indicated, that those signals correspond to final products of carbendazim radiolysis, but they are products of reaction of carbendazim with tert-butanol of structures shown below. 
Fig. 1 a Yield of radiolytic decomposition of aqueous $100 \mu \mathrm{M}$ solutions of carbendazim in different conditions: asterisk aerated solution of pH 7.0 (square) solution at $\mathrm{pH} 7.0$ saturated with $\mathrm{N}_{2} \mathrm{O}$ prior to the irradiation (triangle) argon saturated solution of $\mathrm{pH} 7.0$ with added $106 \mathrm{mM}$ tert-butanol (circle) argon saturated solution at $\mathrm{pH}$ 1.5 with added $106 \mathrm{mM}$ tertbutanol. b Comparison of chromatograms recorded for $100 \mu \mathrm{M}$ solution of carbendazim of $\mathrm{pH} 7.0$ saturated with argon and irradiated in the presence of $106 \mathrm{mM}$ tertbutanol with dose $0.2 \mathrm{kGy}$ (in black) with chromatogram of mixture of standards (in grey) $5 \mu \mathrm{M}$ each: $1-1,2-$ phenylenediamine, 2-2-aminebenzimidazole, 3-2-hydroxybenz-imidazole, 4-benzimidazole, 5-aniline, 6-carbendazim. Detection was carried out at $277 \mathrm{~nm}$.

c Mass spectrum obtained for signal at retention time $14.7 \mathrm{~min}$, identified as spectrum of benzimidazole, recorded for $0.1 \mathrm{mM}$ carbendazim solution of $\mathrm{pH} 7.0$ irradiated with $0.2 \mathrm{kGy}$ dose in aerated solution containing $106 \mathrm{mM}$ tert-butyl alcohol
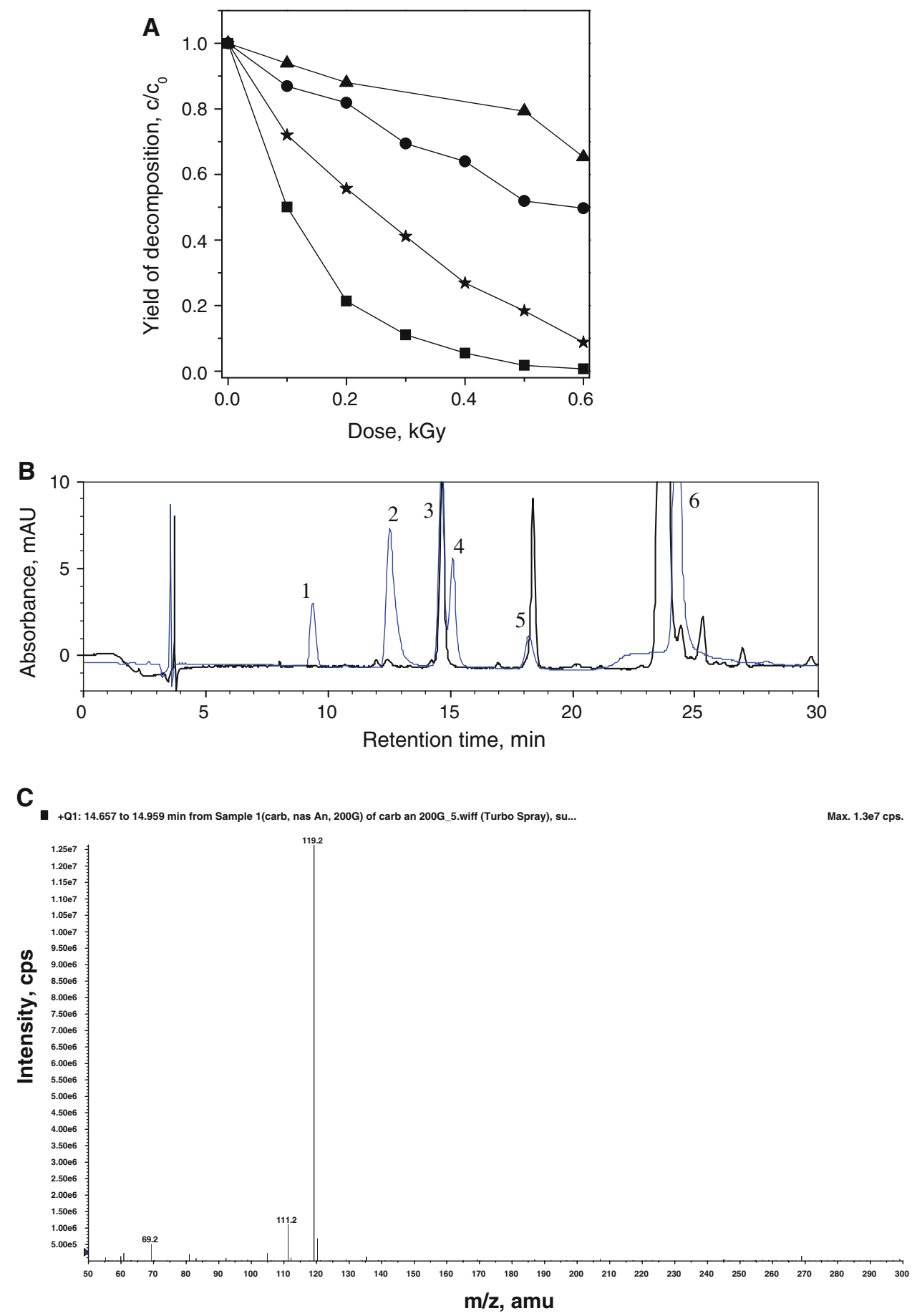<smiles>CC(C)(O)Cc1nc2ccccc2[nH]1</smiles><smiles>CC(C)(C)Oc1nc2ccccc2[nH]1</smiles>

Among ionized final products of carbendazim radiolysis first of all a search for nitrite and nitrate was carried out, which might give some indication how nitrogen from benzimidazole group is transformed during irradiation. For employed dose range up to $600 \mathrm{~Gy}$ in aerated solutions nitrate and nitrate were not found, while trace amounts of ammonium ion were found at 500-600 Gy dose where $100 \mu \mathrm{M}$ carbendazim is completely decomposed. 
Table 2 Radiation chemical yield $(\mathrm{G})$ and dose required for $50 \%$ decomposition $\left(\mathrm{D}_{0.5}\right)$ for radiolytic decomposition of $100 \mu \mathrm{M}$ aqueous solutions of carbendazim by $\gamma$-irradiation under different conditions

\begin{tabular}{lll}
\hline Conditions of irradiation & $\mathrm{G}, \mathrm{mol} \mathrm{J}^{-1}$ & $\mathrm{D}_{0.5}, \mathrm{kGy}$ \\
\hline $\begin{array}{l}\text { Ar saturated solution of pH 7.0 with } \\
\quad 06 \mathrm{mM} \text { tert-butanol }\end{array}$ & 0.123 & $>0.6$ \\
Ar saturated solution of pH 1.5 with & 0.134 & 0.58 \\
$\quad$ 106 mM tert-butanol & & \\
Aerated solution of pH 7.0 & 0.280 & 0.24 \\
$\mathrm{~N}_{2} \mathrm{O}$ saturated solution of pH 7.0 & 0.293 & 0.11 \\
\hline
\end{tabular}

Kinetic modeling of radiolytic decomposition of carbendazim

The results of experiments obtained for radiolytic decomposition of carbendazim under different experimental conditions were compared with model kinetic calculations based on known rate constants for radical reactions. The calculations have been performed with software KINETIC, which was used earlier, e.g. for modeling of a high temperature radiation induced reduction of NO [31], and also for radiolytic decomposition of 2-methyl-chlorophenoxyacetic acid (MCPA) [25]. The computer calculations have been carried out with the use of rate constants for water radiolysis published as reference data [27].

The starting point for first version of modeling was following reaction for carbendazim (MBC) [8]:

$$
\mathrm{MBC}+{ }^{\bullet} \mathrm{OH} \rightarrow \mathrm{MBC}-\mathrm{OH}^{*} \quad k=2,2 \times 10^{9} \mathrm{M}^{-1} \mathrm{~s}^{-1}
$$

and several other reactions based on analogous reactions of compounds of similar structures listed in Table 3. Theoretical modeling might be helpful in finding the most probable decomposition of given target compound in particular experimental conditions. Modeling was focused on calculation of changes of carbendazim concentration as result of decomposition in different conditions of irradiation, including different initial concentrations, different $\mathrm{pH}$ values of irradiated solution, and also conditions for predomination of particular reactive radical species from water radiolysis.

Calculations were performed with different rate-constants taken into consideration. In version II a following reactions were added [32]:

$$
\begin{aligned}
& (\mathrm{MBC}-\mathrm{H})-\mathrm{O}_{2}^{\bullet}(\text { adduct }) \rightarrow \text { PROD } 8 \quad k=10^{5} \mathrm{M}^{-1} \mathrm{~s}^{-1} \\
& (\mathrm{MBC}-\mathrm{OH})-\mathrm{O}_{2}^{\bullet}(\text { adduct }) \rightarrow \text { PROD } 9 \quad k=10^{5} \mathrm{M}^{-1} \mathrm{~s}^{-1} .
\end{aligned}
$$

Based on cited reference [32] it was assumed that in the presence of oxygen in irradiated solutions, the decomposition of carbendazim takes place according to above reactions. In version III of the kinetic modeling, reactions 12 and 13 were deleted, and also the product of reaction 15 in Table 3 was changed, namely the formation of PROD 7 was assumed already in the first stage of reaction, with the same rate constant.

In next version (version IV) products of reaction 11 in Table 3 were changed, namely formation of adduct $\mathrm{MBC}-\mathrm{H}^{\bullet}$ was assumed. The most significant alteration was change of rate-constant value for reaction 5 in Table 3 from $9 \times 10^{8}$ to $9 \times 10^{7} \mathrm{M}^{-1} \mathrm{~s}^{-1}$. According to accepted assumptions in the first stage of decomposition process carbendazim molecule reacts with hydroxyl radicals, and then via formation of several transient species a simpler products are formed.

For each version of modeling and different conditions of irradiation the coefficients of correlation between experimental data and results of modeling were calculated, and they are in the range from 0.93 to 0.995 . Practically all of them can be considered as satisfactory, although the best correlation was obtained in case of version II of modeling.

Table 3 Values of reaction rate constants taken into account in the first attempt of modeling of

\begin{tabular}{|c|c|c|c|}
\hline No. & Reaction & $\begin{array}{l}\text { Rate constant } \\
\left(\mathrm{M}^{-1} \mathrm{~s}^{-1}\right)\end{array}$ & Reference \\
\hline 1 & $\mathrm{MBC}+\mathrm{OH}^{\bullet} \rightarrow \mathrm{MBC}-\mathrm{OH}^{\bullet}($ adduct $)$ & $2.2 \times 10^{9}$ & [8] \\
\hline 2 & $2 \mathrm{MBC}-\mathrm{OH}^{\bullet}($ adduct $) \rightarrow \mathrm{MBC}+\mathrm{PROD} 1+\mathrm{H}_{2} \mathrm{O}$ & $3.0 \times 10^{8}$ & [38] \\
\hline 3 & $\mathrm{MBC}-\mathrm{OH}^{\bullet}($ adduct $)+\mathrm{O}_{2} \rightarrow(\mathrm{MBC}-\mathrm{OH})-\mathrm{O}_{2}^{\bullet}($ adduct $)$ & $3.1 \times 10^{8}$ & [39] \\
\hline 4 & $(\mathrm{MBC}-\mathrm{OH})-\mathrm{O}_{2}($ adduct $) \rightarrow \mathrm{MBC}-\mathrm{OH}^{\bullet}($ adduct $)+\mathrm{O}_{2}$ & $1.2 \times 10^{4} \mathrm{~s}^{-1}$ & \\
\hline 5 & $\mathrm{MBC}+\mathrm{H}^{\bullet} \rightarrow \mathrm{MBC}-\mathrm{H}^{\bullet}($ adduct $)$ & $9 \times 10^{8}$ & [39] \\
\hline 6 & $2 \mathrm{MBC}-\mathrm{H}^{\bullet}($ adduct $) \rightarrow \mathrm{MBC}+\mathrm{PROD} 2$ & $3 \times 10^{8}$ & [38] \\
\hline 7 & $\mathrm{MBC}-\mathrm{OH}^{\bullet}($ adduct $)+\mathrm{MBC}-\mathrm{H}^{\bullet}($ adduct $) \rightarrow \mathrm{MBC}+\mathrm{PROD} 3$ & $3 \times 10^{8}$ & [38] \\
\hline 8 & $\mathrm{MBC}-\mathrm{H}^{\bullet}($ adduct $)+\mathrm{O}_{2} \rightarrow(\mathrm{MBC}-\mathrm{H})-\mathrm{O}_{2}^{\bullet}($ adduct $)$ & $3.1 \times 10^{8}$ & [39] \\
\hline 9 & $(\mathrm{MBC}-\mathrm{H})-\mathrm{O}_{2}^{\bullet}($ adduct $) \rightarrow \mathrm{MBC}-\mathrm{H}^{\bullet}($ adduct $)+\mathrm{O}_{2}$ & $1.2 \times 10^{4}$ & \\
\hline 10 & $\mathrm{MBC}+e_{\mathrm{aq}} \rightarrow \mathrm{MBC}^{\bullet}$ & $1.2 \times 10^{7}$ & [39] \\
\hline 11 & $\mathrm{MBC}^{\bullet}+\mathrm{H}^{+} \rightarrow \mathrm{PROD} 4$ & $1.2 \times 10^{10}$ & [8] \\
\hline 12 & $\mathrm{~N}_{2} \mathrm{O}+e_{\mathrm{aq}} \rightarrow \mathrm{N}_{2}+\mathrm{OH}^{\bullet}+\mathrm{OH}^{-}$ & $9.1 \times 10^{9}$ & [30] \\
\hline 13 & $t-$ butanol $+\mathrm{OH}^{\bullet} \rightarrow$ PROD 5 & $5.3 \times 10^{8}$ & [30] \\
\hline 14 & $t-$ butanol $+\mathrm{H} \rightarrow$ PROD 6 & $1.2 \times 10^{6}$ & [30] \\
\hline 15 & $t-$ butanol $+e_{\mathrm{aq}} \rightarrow t-$ butanol $-+\mathrm{H}^{+} \rightarrow$ PROD 7 & $10^{4}$ & [30] \\
\hline
\end{tabular}
decomposition of carbendazim by ionizing radiation 
The developed model of radiolytic decomposition of carbendazim confirmed a linear dependence of absorbed dose required for decomposition of carbendazim on its concentration from 20 to $100 \mu \mathrm{M}$, and independence of the decomposition yield on $\mathrm{pH}$ of irradiated solutions.

As it can be seen form plots in Fig. 2, graphically comparing results of experiments and calculations, the largest yield of radiolytic decomposition of carbendazim is obtained in conditions where oxidative radicals predominate.

Mechanism of decomposition of carbendazim by $\gamma$-irradiation

Depending on chemical conditions of carrying out the irradiation process, different products were identified under oxidative and reductive conditions and this is summarized in the scheme below.
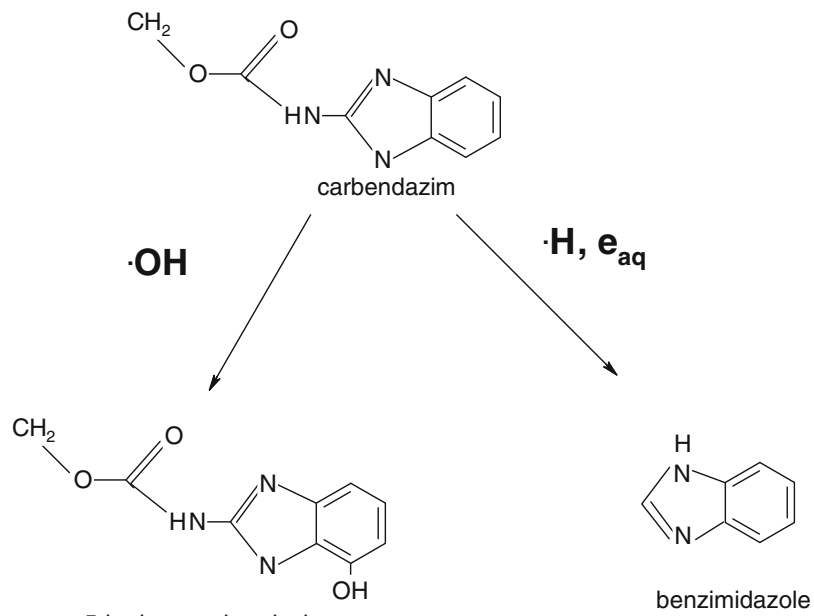

5-hydroxycarbendazim

$+$

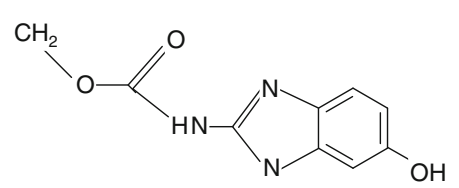

4-hydroxycarbendazim

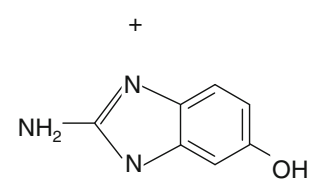

2-aminobenzimidazole

$+$

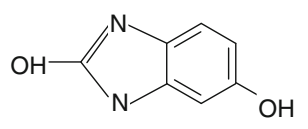

2-hydroxybenzaimdazole
Formation of the same final products of decomposition under oxidative conditions, suggests similar mechanism of decomposition process as was postulated for $\mathrm{UV} / \mathrm{H}_{2} \mathrm{O}_{2}$ photochemical oxidation by Mazellier et al. [8]. Two sites of hydroxyl radical attack are possible in carbendazim molecule: the aromatic ring and the hydrogen atoms of methoxy group. In case of attack to the aromatic ring, in the first stage the radical adduct is formed, which undergoes oxidation to hydroxycarbendazim with its two stable isomers. These products were identified in radiolytic process, which proves this path of reaction. The formation of this adduct was also assumed in modeling. Additionally, when the formation of hydroxyl derivatives of carbendazim was observed, also formation of 2-hydroxybenzimidazole was found. This is in contrary to processes carried out under reductive conditions, where the main products at the examined absorbed dose are benzimidazole and 2-aminobenzimidazole.

Changes of toxicity of irradiated carbendazim solutions

Monitoring of toxicity changes during radiolytic processes of decomposition of environmental pollutants is essential for proper judgment of suitability of given treatment for environmental protection. It is widely known that decomposition of organic pollutants may in different stages of the process lead to the formation of more toxic products than the irradiated pollutant [33]. Although carbendazim is considered as highly toxic to aquatic organisms, it is much less toxic to mammals (WHO Class III), however, it is also considered as teratogenic agent [5], and from other side as a novel anticancer drug [34].

In this study three different toxicity tests were applied for the monitoring of toxicity changes of carbendazim solutions during irradiation processes. With Microtox ${ }^{\circledR}$ test for $0.52 \mathrm{mM}$ solution of carbendazim, and also solutions of its degradation products 1,2-phenylenediamine, 2-aminobenzimidazole, 2-hydroxybenzimidazole and benzimidazole, no toxicity has been measured.

Chemical structure of carbendazim containing benzimidazole ring indicates possible toxicity to mentioned already aquatic organisms $[35,36]$, hence it seems to be more appropriate to employ in this case Daphnia magna test, used already for toxicity studies of carbendazim [37]. Figure $3 \mathrm{a}$ shows results of toxicity measurements with Daphtoxkit ${ }^{\circledR}$ obtained in this work for radiolytic decomposition of carbendazim. It was also found that most toxic among examined species is carbendazim. EC50 value for $24 \mathrm{~h}$ test for carbendazim was $2.35 \mu \mathrm{M}$, while for benzimidazole and 2-hydroxybenzimidazol was above $100 \mathrm{mg} \mathrm{L}^{-1}$, and for 2-aminobenzimidazole $19.3 \mathrm{mg} \mathrm{L}^{-1}$. Irradiation of $100 \mu \mathrm{M}$ solution of carbendazim with 
Fig. 2 Comparison of experimental data on efficiency of decomposition of carbendazim in $100 \mu \mathrm{M}$ solutions in various chemical conditions using $\gamma$ irradiation with data obtained by kinetic modeling: a solution for irradiation of $\mathrm{pH} 7,0$ saturated with $\mathrm{N}_{2} \mathrm{O}$ (square-exprimental, asterisk-calculated versions I-IV, b aerated solution $\mathrm{pH} 7,0$ (square-experimental, asteriskcalculated versions I and III, left pointed triangle-calculated version IV, upward trianglecalculated version II), c solution of $\mathrm{pH}$ 7,0 saturated with argon, and added $106 \mathrm{mM}$ tert-butanol (square-experimental, inverted triangle-calculated version III, upward triangle-calculated versions I and II, left pointed triangle-calculated version IV), d solution of $\mathrm{pH} 1.5$ saturated with argon and with added $106 \mathrm{mM}$ tert-butanol (squareexperimental, upward trianglecalculated versions I and II, inverted triangle-calculated version III, left pointed trianglecalculated version IV)
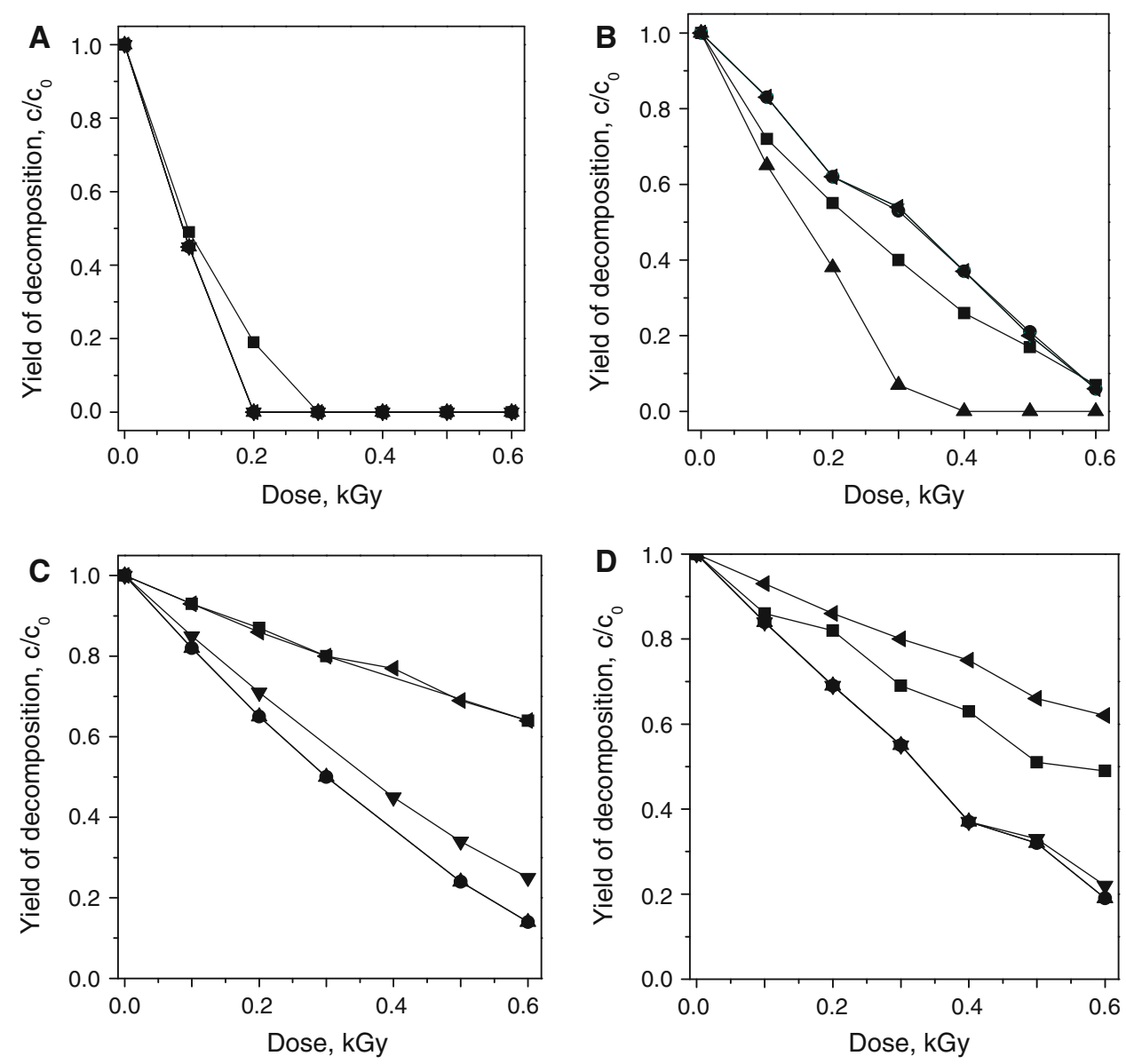

$0.1 \mathrm{kGy}$ dose increases toxicity by four times, while at dose $0.6 \mathrm{kGy}$ where complete decomposition of carbendazim occurs, toxicity in $24 \mathrm{~h}$ test is about four times smaller than for the initial solution. The initial increase of toxicity for small doses can be attributed to formation of transient, more toxic, by-products of which identification requires further studies.

As additional way of the monitoring the toxicity changes during irradiation of carbendazim solutions the cellular test employing commercially available human leukemia cells was used. It is based on reduction of tetrazolium salt in cellular mitochondria. In order to observe hindering the growth of cells the measurements of cytostatic activity of carbendazim were carried out without irradiation in wide range of concentrations. Obtained data shown in Fig. 3b indicate that EC50 for carbendazim is at the level of $40 \mu \mathrm{M}$, confirming high toxicity of carbendazim measured with daphniae. Cytostatic acivity was also measured for irradiated solutions of carbendazim at initial concentrations of 20 and $100 \mu \mathrm{M}$ in aerated solutions of $\mathrm{pH}$ 7.0. As it is shown in Fig. 3c for absorbed doses $0.3-0.5 \mathrm{kGy}$ toxicity significantly increased (no alive cells were observed), while for $1.0 \mathrm{kGy}$ is smaller than for the initial carbendazim solution. Non-monotonous changes of toxicity are resultant of concentration changes of numerous transient by-products, more or less stable, which occur at different doses and exhibit different toxicity.

Irradiation of industrial wastes from production of carbendazim

The industrial production of carbendazim is carried out in two-stage process. In the first step of the process the sodium salt of methyl $\mathrm{N}$-cyanocarbamate is formed as product of the reaction of cyanamide with methyl chloroformate and sodium hydroxide in aqueous solution. Then in the second stage, this salt in condensation reaction with o-phenylenediamine hydrochloride in hydrochloric acid solution produces carbendazim, which is then filtered.

The main organic components of examined wastes produced in these processes are 2-aminobenzimidazole (2$\mathrm{AB})$, 2-hydroxybenzimidazole (2-HB) and carbendazim 

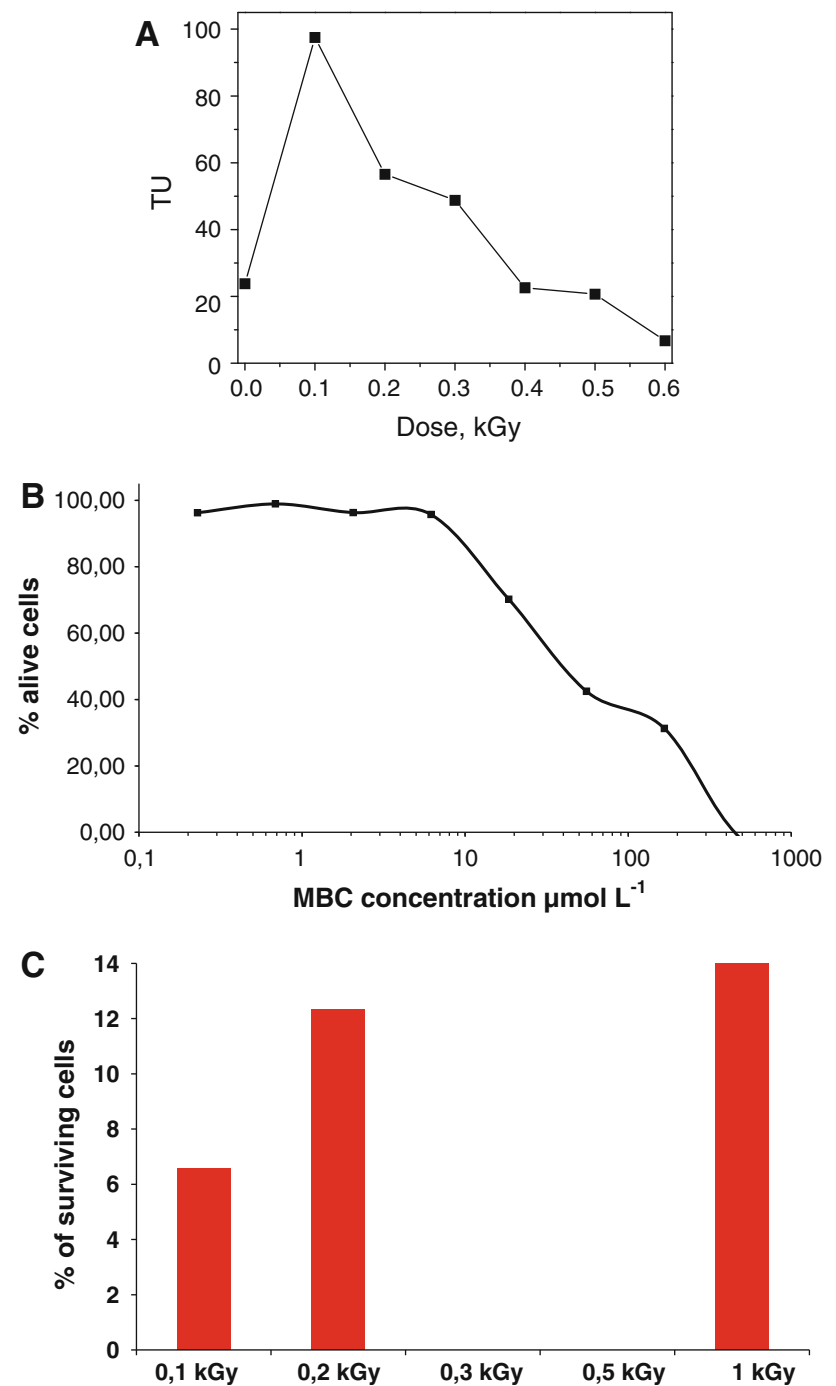

Fig. 3 a Changes of toxicity ( $24 \mathrm{~h}$ test) measured in terms of absorbed dose with Daphtoxkit for $100 \mu \mathrm{M}$ solutions of carbendazim of $\mathrm{pH} 7.0$ irradiated in aerated solutions with different doses. b The effect of carbendazim on restriction of growth of human leukemia test cells. c Effect of cytostatic activity of $20 \mu \mathrm{M}$ carbendazim solution of $\mathrm{pH} 7.0$ in terms of applied radiation dose observed for human leukemia test cells

(MBC) of concentrations in the range $0.5-1.0 \mathrm{~g} / \mathrm{L}$. In comparison to standard mixture the chromatogram recorded for 20-fold diluted raw wastewater shows the presence of large number of some other unidentified components. The irradiation of raw non-diluted waste with $50 \mathrm{kGy}$ dose results only in about $20 \%$ decrease of content of main components of waste.

If the waste is diluted prior to the irradiation, really lower dose is needed, and larger amount should be irradiated. The changes of concentrations of three main identi- fied components of wastes as result of irradiation of aerated solutions 10 and 20 times diluted with water are shown in Fig. 4a-c, and corresponding chromatograms are shown in Fig. 4d. At $26 \mathrm{kGy}$ dose carbendazim at initial concentration $42 \mu \mathrm{M}$ was completely decomposed, while at dose $50 \mathrm{kGy} 90 \%$ of $2-\mathrm{HB}$ and $98 \%$ of $2-\mathrm{AB}$ were also decomposed.

\section{Conclusions}

Carbendazim, commonly used fungicide, is anthropogenic pollutant especially dangerous for aquatic systems. Its radiolytic decomposition was not, so far, described in the literature, in spite of its wide use, slow biodegradation in natural media and widely reported toxicity. In earlier experiments reported on different Advanced Oxidation Processes it was shown, that the most efficient decomposition results from reaction of carbendazim with hydroxyl radicals. The products identified by HPLC and LC-MS methods implicate that mechanism of decomposition is similar to that observed in photochemical oxidation, but in contrary to photochemical processes the yield of decomposition does not depend on the acidity of irradiated solutions. The radiolytic decomposition of carbendazim residues present in micromolar level requires relatively small doses of radiation (below $1 \mathrm{kGy}$ at initial concentration $100 \mu \mathrm{M})$. Compared to the photolytic processes the advantage of radiolytic processes is also their short time, while, e.g. for the photochemical decomposition of carbendazim it requires 50-150 min for initial concentration $20 \mu \mathrm{M}$ depending on $\mathrm{pH}$ of irradiated carbendazim solution $[6,10]$. The possibility of providing a large energy causes, that radiolytic processes are relatively slightly affected by changes of concentration and type of other substances present in a given media.

The mechanism of radiolytic decomposition, involving numerous parallel radical reactions was confirmed by kinetic modeling, for which a very good agreement was obtained with the experimental data.

During the radiolysis experiments the toxicity changes were also monitored using three different methods, which allows versatile evaluation of the method from the environmental point of view. Among them the pioneering application of human leukemia cells was employed.

The reported example application of radiolytic method for decomposition of carbendazim in industrial wastes indicates the possibility of technological applications of the 

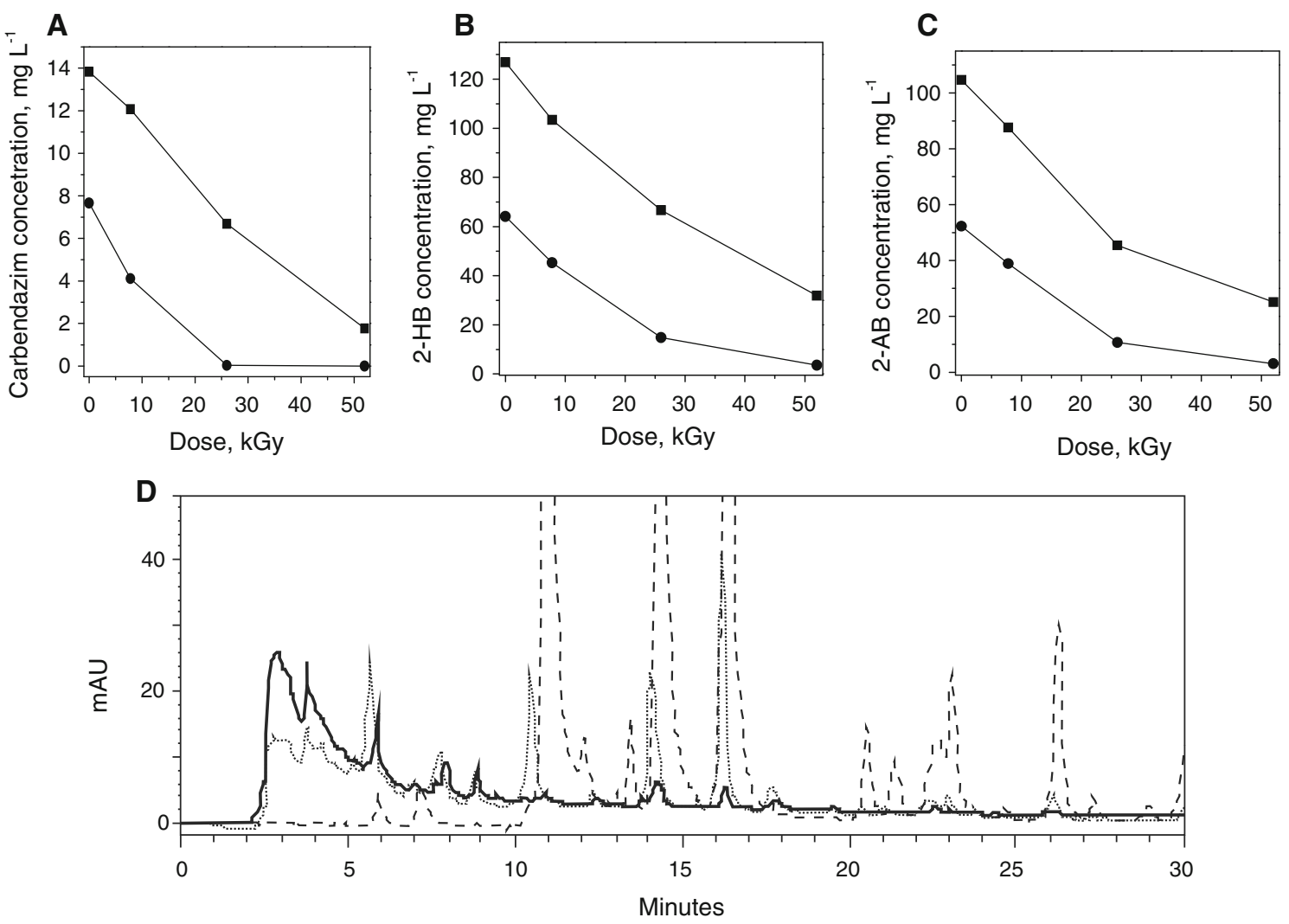

Fig. 4 Effect of irradiation with different doses on concentration of main components of industrial waste obtained by irradiation of 20 times-diluted wastewater: a carbendazim, b 2-hydroxybenzimidazole, c 2-aminobenzimidazole. d Chromatograms recorded for 1:20 diluted

developed method, especially when $\gamma$-radiation is replaced by the use of beam of accelerated electrons, which significantly shortens whole process.

Open Access This article is distributed under the terms of the Creative Commons Attribution Noncommercial License which permits any noncommercial use, distribution, and reproduction in any medium, provided the original author(s) and source are credited.

\section{References}

1. Delp CJ (1987) Modern selective fungicides. Wiley, London

2. Tomlin C (1994) The Pesticide Manual, 10th ed, British Crop Protection Council, Brac-knell

3. Nakai M, Toshimori K, Yoshinaga K, Nasu T, Hess RA (1998) Carbendazim-induced abnormal development of the acrosome during early phases of spermiogenesis in the rat testis. Cell Tissue Res 294:145-152

4. Lim L, Miller MG (1997) The role of the benomyl metabolite carbendazim in benomyl-induced testicular toxicity. Toxicol Appl Pharm 142:401-410

5. Mantovani A, Maranghi F, Ricciardi C, Macri C, Stazi AV, Attias L, Zappomi GA (1998) Developmental toxicity of carbendazim: comparison of no-observed-adverse-effect level and benchmark dose approach. Food Chem Toxicol 36:37-45 industrial wastes from production of carbendazim irradiated with electron beam: prior to the irradiation (broken line), irradiated with $26 \mathrm{kGy}$ dose (dotted line), and $52 \mathrm{kGy}$ dose(solid line), where: 1 aminobenzimidazole, 2-2-hydroxybenzimidazole, 3-carbendazim

6. Boudina A, Emmelin C, Baaliouamer A, Grenier-Loustalot MF, Chovelon JM (2003) Photochemical behaviour of carbendazim in aqueous solution. Chemosphere 50:649-655

7. Mazellier P, Leroy E, De Laat J, Legube B (2002) Transformation of carbendazim induced by the $\mathrm{H}_{2} \mathrm{O}_{2} / \mathrm{UV}$ system in the presence of hydrogenocarbonate ions: involvement of the carbonate radical. New J Chem 26:1784-1790

8. Mazellier P, Leroy E, De Laat J, Legube B (2003) Degradation of carbendazim by $\mathrm{UV} / \mathrm{H}_{2} \mathrm{O}_{2}$ investigated by kinetic modeling. Environ Chem Lett 1:68-72

9. Fleeker JR, Lacy HM (1977) Photolysis of methyl 2-benzimidazolecarbamate. J Agric Food Chem 25:51-55

10. Pandes R, Ibarz A, Esplugas S (2000) Photodecomposition of carbendazim in aqueous solutions. Wat Res 34:2951-2954

11. Escalada JP, Pajares A, Gianotti J, Massad WA, Bertolotti S, Amat-Guerri F, Garcia NA (2006) Dye-sensitized photodegradation of the fungicide carbendazim and related benzimidazoles. Chemosphere 65:237-244

12. Zieliński J (2001) PhD Thesis, Technical University of Warsaw, Department of Chemical and Process Engineering, Warsaw, Poland

13. Chiba M, Singh RP (1986) High-performance liquid chromatography method for simulta-neous determination of benomyl and carbendazim in aqueous media. J Agric Food Chem 34:108-112

14. Halko R, Padron Sanz C, Sosa Ferrera Z, Santana Rodriquez JJ (2004) Determination of benzimidazole fungicides by HPLC with fluorescence detection after micellar extra-ction. Chromatographia 60:151-156 
15. Makihata N, Kawamoto T, Teranishi K (2003) Simultaneous analysis of carbamate pesticides in tap and raw water by LC/ESI/ MS. Anal Sci 19:543-549

16. Nozal MJ, Bernal JL, Jiménez JJ, Martin MT, Bernal J (2005) Determination of azolic fungicides in wine by solid-phase extraction and high-performance liquid chromatography-atmospheric pressure chemical ionization-mass spectrometry. J Chromatogr A 1076:90-96

17. Tharsis N, Portillo JL, Broto-Puig F, Comellas L (1997) Simplified reversed-phase conditions for the determination of benzimidazle fungicides in fruits by high-performance liquid chromatography with UV detection. J Chromatogr A 78:95-101

18. Prousalis KP, Polygenis DA, Syrokou A, Lamari FN, Tsegenidis $T$ (2004) Determination of carbendazim, thiabendazole and o-phenylphenol residues in lemons by HPLC following sample clean-up by ion-pairing. Anal Bioanal Chem 379:458-463

19. Hogendoorn EA, Westhuis K, Dijkman E, Heusinkveld HAG, Chemraskul P, Biadul P, Baumann RA, Cornelese AA, Van der Linden MA (2000) Determination of carbendazim in water, soil and sediment samples by RPLC with and without column switching and various spectrometric detection. Int J Environ Anal Chem 78:67-85

20. Trojanowicz M, Chudziak A, Bryl-Sandelewska T (1997) Use of reversed-phase HPLC with solid-phase extraction for monitoring of radiolytic degradations of chlorophenols for environmental protection. J Radioanal Nucl Chem 224:131-136

21. Trojanowicz M, Drzewicz P, Panta P, Głuszewski W, NałęczJawecki G, Sawicki J, Sampa MHO, Oikawa H, Borrely SI, Czaplicka M, Szewczyńska M (2002) Radiolytic degradation and toxicity changes in $\gamma$-irradiated solutions of 2,4-dichlorophenol. Radiat Phys chem 65:357-366

22. Drzewicz P, Trojanowicz M, Zona R, Solar S, Gehringer P (2004) Decomposition of 2,4-dichlorophenoxyacetic acid by ozonation, ionizing radiation as well as ozonation combined with ionizing radiation. Radiat Phys chem 69:281-287

23. Drzewicz P, Gehringer P, Bojanowska-Czajka A, Zona R, Solar S, Nałęcz-Jawecki G, Sawicki J, Trojanowicz M (2005) Radiolytic degradation of the herbicide dicamba for environmental protection. Arch Environ Contam Toxicol 48:311-322

24. Bojanowska-Czajka A, Drzewicz P, Kozyra C, Nałęcz-Jawecki G, Sawicki J, Szostek B, Trojanowicz M (2006) Radiolytic degradation of herbicide 4-chloro-2-methyl phenoxy-acetic acid (MCPA) by $\gamma$-radiation for environmental protection. Ecotox Environ Safety 65:265-277

25. Bojanowska-Czajka A, Drzewicz P, Zimek Z, Nichipor H, Nałęcz-Jawecki G, Sawicki J, Kozyra C, Trojanowicz M (2007) Radiolytic degradation of pesticide 4-chloro-2-methyl-phenoxyacetic acid (MCPA) - Experimental data and kinetic modeling. Radiat Phys chem 76:1806-1814

26. Moghaddam MF, Trubey RK, Anderson JJ (2000) An LC/MS/ MS method for improved quantitation of the bound residues in the tissues of animals orally dosed with $\left[{ }^{14} \mathrm{C}\right]$ benomyl. J Agric Food Chem 48:5195-5199

27. Buxton GV, Greenstock CL, Helman WP, Ross AB (1988) Critical review of rate con-stants for reaction of hydrated electrons, hydrogen atoms and hydroxyl radicals $\left(\mathrm{OH}^{\bullet} / \mathrm{O}^{\bullet-}\right)$ in aqueous solution. J Phys Ref Data 17:513-531

28. Mallat E, Barcelo D, Tauler R (1997) Degradation study of benomyl and carbendazim in water by liquid chromatography and multivariate curve resolution methods. Chromato-graphia 46: $342-350$

29. Wojnarovits L, Takacs E, Dajka K, Emmi SS, Russo M, D'Angelantonio M (2004) Re-evaluation of the rate constant for the $\mathrm{H}$ atom reaction with tert-butanol in aqueous solution. Radiat Phys chem 69:217-219

30. Pikaev AK (1986) Modern radiation chemistry. Radiolysis of gases and solutions, Nauka, Moscow

31. Nichipor H, Dashouk E, Yermakov A (1999) Computer simulation of the kinetics of high temperature radiation induced reduction of NO. Radiat Phys chem 54:307-315

32. Zona R, Solar S, Sehested K, Holeman J, Mezyk SP (2002) OHradical induced oxidation of phenoxyacetic acid and 2,4-dichlorophenoxyacetic acid. Primary radical steps and products. J Phys Chem A 106:6743-6749

33. Boxall ABA, Fenner K, Kolpin DW, Maund S (2004) When synthetic chemicals degrade in the environment. Env Sci Technol 38:369-375

34. Jia L, Wong H, Wang Y, Garza M, Weitman SD (2002) Carbendazim: disposition, cellular permeability, metabolite identification, and pharmacokinetic comparison with its nanoparticle. J Pharm Sci 92:161-172

35. Cuppen GM, Van den Brink PJ, Camps E, Uil KF, Brock TCM (2000) Impact of the fungicide carbendazim in freshwater microcosms. I. Water quality, breakdown of parti-culate organic matter and responses of macroinvertebrates. Toxicology 48: 233-250

36. Van den Brink PJ, Hattink J, Bransen F, Van Donk E, Brock TCM (2000) Impact of the fungicide carbendazim in freshwater microcosms. II. Zooplankton, primary producers and final conclusions. Aquatic Toxicol 48:251-264

37. Slijkerman AME, Baird DJ, Conrad A, Jak RG, Van Straalen NM (2004) Assessing structural and functional plankton responses to carbendazim toxicity. Environ Toxicol Chem 23:455-462

38. Stafford N, Gray KA, Kamat PV (1994) Radiolytic and $\mathrm{TiO}_{2}-$ assisted photocatalytic degradation of 4-chlorophenol. A comparative study. J Phys Chem 98:6343-6351

39. Pan XM, Schuchmann MN, von Sonntag C (1993) Oxidation of benzene by the $\mathrm{OH}$ radical. A product and pulse radiolysis study in oxygenated aqueous solution. J Chem Soc Perkin Trans 2: 289-297 